The Open Public Health Journal
CrossMark
Content list available at: www.benthamopen.com/TOPHJ/
DOI: $10.2174 / 1874944501609010009$

RESEARCH ARTICLE

\title{
Cancer Patient's Contribution to Reduce Chemotherapy Related Burden of Travel: What Would Chemotherapy Patients Agree to Do?
}

\author{
P. Groux ${ }^{1, *}$, S. Anchisi ${ }^{2}$ and T. Szucs ${ }^{3}$ \\ ${ }^{1}$ Kundengerecht ch GmbH, Alpenstrasse 22, 4950 Huttwil, Switzerland \\ ${ }^{2}$ Département de Médecine Interne et Gériatrie, Service D’oncologie, CHVR - Hôpital du Valais, Avenue de Grand- \\ Champsec 80, 1951 Sion, Switzerland \\ ${ }^{3}$ European Center of Pharmaceutical Medicine, University of Basel, Klingelbergstrasse 61, 4056 Basel, Switzerland
}

Received: December 31, 2015

Revised: April 29, 2016

Accepted: May 18, 2016

\begin{abstract}
:
Objective:

Many patients describe travel to cancer treatment as inconvenient and a practical hardship and it may be perceived or experienced as a barrier to treatment. We investigated whether all patients who came for chemotherapy would theoretically accept an alternative solution to reduce the number of journeys. The aim was to characterize and quantify the acceptance of these alternatives and to identify groups of patients who could be interested in alternative solutions.
\end{abstract}

\section{Method:}

All patients coming in February 2012 for chemotherapy to one of the four centres of the hospital or to the unique private practice were asked to answer a survey. Eight options to reduce the number of travels were proposed to patients undergoing chemotherapy with five possible answers "Yes", "rather yes", "rather no", "No" and "I don't know". Impact of travel time, gender, age and the number of persons living in the same household on the results was analysed.

\section{Results:}

130 patients $(62 \%)$ answered all requested questions. Acceptance of offered options varies from not acceptable at all to acceptable for a small majority of patients. Distance to travel impacts the answers for some options.

\section{Conclusion:}

Some alternatives were acceptable for some groups of patients. Particularly the transfer of the drug intake to the practice of the family doctor or preferably at home of the patient enjoyed some acceptance. These options should be investigated in further studies.

Keywords: Burden of travel, Cancer, Chemotherapy, Elder patients, Patient's preferences.

\section{INTRODUCTION}

Many patients describe travel to cancer treatment as inconvenient and a practical hardship and it may be perceived or experienced as a barrier to treatment [1]. The need to travel for treatment cause many practical, emotional and financial problems for patients and burden them with additional worry concerning family and work commitments [2]. Recent publications highlighted as well travel-related burden for cancer patients [3] and financial and social impacts for support persons of cancer survivors [4] as impact of age and distance on the willingness cancer patients to travel

\footnotetext{
* Address correspondence to this author at the Kundengerecht ch GmbH, Alpenstrasse 22, 4950 Huttwil, Switzerland; Tel: +41 792031411 ; E-mail: philippe.groux@kundengerecht.ch
} 
more or further away for a slightly more efficient therapy [5]. Haematological cancer survivors living in a nonmetropolitan location are reported to have 17 times the odds of reporting locational or financial barriers compared to survivors leaving in a metropolitan area [6]. Cancer patients address access problems as well with their general practitioners as with their medical oncologists [7]. The use of the less travelling intensive hypofractionated breast radiotherapy versus conventional breast radiotherapy is correlated with the distance to the clinic [8]. Some reports reveal that an average of $20-30 \%$ of North American women forego radiotherapy after receiving lumpectomy [9, 10], or choose mastectomy over breast preservation [11] due to the several factors, including age, psychological distress, quality of life concerns, and cost of undergoing daily radiotherapy during several weeks [12].

The Swiss health system is based on principles of free demand and supply as well as regulated competition [13] with a fee-for-service system for the reimbursement. As travel costs are not reimbursed they can increase the financial burden for patients living in remote areas. Valais is a Swiss alpine canton at the southern border of the country and consists in a main valley and the valleys of several feeder rivers. The population of the upper part of the valley speaks German, the population in the middle and the lower part of the valley speaks French. All cancer treatments are offered in places in the main valley. A former study emphasized transport issues as a major obstacle to cancer treatment [14].

We investigated whether all patients who came in February 2012 for chemotherapy would theoretically accept an alternative solution to reduce the number of journeys. The aim was to characterize and quantify the acceptance of these alternatives and to identify groups of patients who could be interested in alternative solutions.

Approval for the study was obtained from the medical-ethical commission of the canton of Valais.

\section{METHODS}

All patients coming in February 2012 for consultation or ambulatory treatment to one of the four centres of the Hôpital du Valais or to the unique private practice in the region were proposed to answer a survey. Patients were asked to fill out the questionnaire at least once per centre. If a patient came up in two different centres he was asked to answer in both centres. The questionnaire covered items as gender, date of birth, living place, kind of cancer, kind of treatment and questions covering different aspects of the travel: how the patient travelled to the centre, how long the travel lasted and which kind of support was necessary to travel and who provided this support. Details of the questionnaire have been published separately [15].

A dedicated question with eight options to reduce the number of travels was proposed to chemotherapy patients:

To reduce the number of travels would you agree to?

1. Choose a therapy which is slightly less efficacious

2. Choose a therapy with slightly more side effects

3. To get a more expensive therapy and partially contribute to the costs

4. Renounce to the therapy

5. To be treated by a not specialized physician who's practice is closer to your home

6. To get the drugs administered in the practice of your family doctor

7. To get the drugs administered at home

8. To be hospitalized

With the possible answers
1. Yes
2. Rather yes
3. Rather no
4. No
5. I don't know

To be included in the analysis patients must have answered to at least one of these options and given their age, gender, how long the journey lasted and confirmed that they came for chemotherapy. Patients who came for other reasons were not considered for this study as some options are typically chemotherapy-related. Two patients answered twice to the questionnaire at the same site, only the first questionnaire was considered. No patient answered to the questionnaire in more than one site. Criteria for exclusion are summarized in Table $\mathbf{1 .}$ 
Table 1. Criteria for exclusion from analysis. 14 patients fulfilled two or more criteria to be excluded.

\begin{tabular}{|l|c|}
\hline Reason for exclusion from analysis & Number \\
\hline Birthday missing & $3(1 \%$ of all patients $)$ \\
\hline Gender missing & $16(8 \%)$ \\
\hline Living place missing & $4(2 \%)$ \\
\hline No answer to at least one mandatory question & $57(27 \%)$ \\
\hline Contradictory answer $*$ & $13(6 \%)$ \\
\hline Not a cancer patient & $1(1 \%)$ \\
\hline Not living in Valais & $1(1 \%)$ \\
\hline
\end{tabular}

*Patients who answered they came alone and named an accompanying person in the sub question were considered with contradictory answers.

The data were summarized and analyzed using Microsoft Excel and EpiData Analysis (Epidata Association, Odense, Denmark). Crude odd ratios were calculated from a $2 \times 2$ table. The odds ratio (OR), its standard error and $95 \%$ confidence interval are calculated according to Kirkwood and Sterne [16].

\section{RESULTS}

211 chemotherapy patients participated to the survey and 130 different patients answered to the requested questions for this publication (62\%). Patient characteristics are summarized in Table 2.

Table 2. Patients characteristics. 130 patients answered all requested questions.

\begin{tabular}{|c|c|}
\hline Characteristics & Result \\
\hline $\begin{array}{l}\text { Gender } \\
\text { Women } \\
\text { Men }\end{array}$ & $\begin{array}{l}68(52 \%) \\
62(48 \%)\end{array}$ \\
\hline $\begin{array}{l}\text { Median age } \\
\text { Women } \\
\text { Men }\end{array}$ & $\begin{array}{l}66 \text { years } \\
63 \text { years } \\
67 \text { years }\end{array}$ \\
\hline Age range & 19 to 86 years old \\
\hline $\begin{array}{l}\text { Language } \\
\text { French } \\
\text { German }\end{array}$ & $\begin{array}{l}96(74 \%) \\
34(26 \%)\end{array}$ \\
\hline $\begin{array}{l}\text { Type of cancer in women } \\
\text { Breast } \\
\text { Lung } \\
\text { Colorectal } \\
\text { Skin } \\
\text { Others } \\
\text { Not answered }\end{array}$ & $\begin{array}{c}23(34 \%) \\
12(18 \%) \\
7(10 \%) \\
1(1 \%) \\
25(37 \%) \\
0(0 \%)\end{array}$ \\
\hline $\begin{array}{l}\text { Type of cancer in men } \\
\text { Colorectal } \\
\text { Prostate } \\
\text { Lung } \\
\text { Skin } \\
\text { Others } \\
\text { Not answered }\end{array}$ & $\begin{array}{c}13(21 \%) \\
10(16 \%) \\
4(6 \%) \\
1(2 \%) \\
32(52 \%) \\
2(3 \%)\end{array}$ \\
\hline $\begin{array}{l}\text { Distance to treatment centre } \\
\text { below } 15 \text { minutes } \\
\text { between } 15 \text { and } 30 \text { minutes } \\
\text { between } 30 \text { and } 60 \text { minutes } \\
\text { more than } 60 \text { minutes }\end{array}$ & $\begin{array}{c}58(45 \%) \\
43(33 \%) \\
22(17 \%) \\
7(5 \%)\end{array}$ \\
\hline
\end{tabular}

To compare the different options a score was created, giving the value 1 to "Yes", 0.5 to "rather yes", -0.5 to "rather no" and -1 to "No". The number of answers was multiplied with the value, added together and this total was divided by the number of answers. Results are summarized in Table $\mathbf{3}$.

Table 3. Summary of the answers and overall score per option. Options are classified by score.

\begin{tabular}{|l|c|c|c|c|c|c|}
\hline Options & NO & Rather NO & $\begin{array}{c}\text { Rather } \\
\text { YES }\end{array}$ & $\begin{array}{c}\text { YES } \\
\text { I don't } \\
\text { know }\end{array}$ & $\begin{array}{c}\text { No answer } \\
\text { SCORE }\end{array}$ \\
\hline Renounce to therapy & 76 & 26 & 1 & 0 & 11 & 16 \\
\hline
\end{tabular}


(Table 3) contd.....

\begin{tabular}{|c|c|c|c|c|c|c|c|}
\hline Options & NO & Rather NO & $\begin{array}{c}\text { Rather } \\
\text { YES }\end{array}$ & YES & $\begin{array}{l}\text { I don't } \\
\text { know }\end{array}$ & No answer & SCORE \\
\hline Slightly less efficacious therapy & 74 & 27 & 4 & 2 & 16 & 7 & -0.7 \\
\hline Non specialized physician & 64 & 29 & 3 & 12 & 7 & 15 & -0.6 \\
\hline Slightly more side effects & 40 & 49 & 8 & 3 & 16 & 14 & -0.5 \\
\hline Be hospitalized & 41 & 44 & 7 & 12 & 12 & 14 & -0.4 \\
\hline More expensive therapy and pay a part of the costs & 35 & 37 & 20 & 8 & 18 & 12 & -0.3 \\
\hline Get drug in family doctor practice & 33 & 33 & 16 & 24 & 9 & 15 & -0.2 \\
\hline Get drug at home & 24 & 22 & 21 & 41 & 7 & 15 & +0.1 \\
\hline
\end{tabular}

To renounce to the treatment is not an option for these patients. Only one patient answered "rather yes". To renounce to efficacy isn't acceptable as well in a similar extent. Being treated by a non-specialized physician isn't an option for a vast majority. 15 patients were open to this option (12\%). All 15 patients were French speaking whilst none of the German speaking was favourable to this option.

The idea to accept more side effects to reduce the number of journeys leads to more differentiated answers. Negative answers are a clear majority, even if the cautious "rather no" is slightly more numerous than the clear "no". Patients living more than an hour from the treatment place are favourable to this option.

To be hospitalized is an interesting option for $15 \%$ of the patients. Acceptance tend to be higher for patients living alone (24\%) as for patients living in a multi-person household (12\%), without being statistically significantly different. Patients living alone have also a higher acceptance of paying partially for a more expensive therapy to reduce the number of journeys. Positive and negative votes are almost balanced in this patient group, whilst negative votes are three times more frequent in the other patient group.

Getting the drugs, which must be prescribed by the medical oncologist, in the practice of the family doctor is interesting for some patients. A tiny majority of 66 patients is unfavourable to it, the unfavourable patients are for the majority living rather close to the treatment place (less than 30 minutes), whilst patients leaving further away are slightly more favourable to it (14 positive votes $v s .11$ negative ones). All patients living more than 60 minutes of the treatment place are not in favour of this option.

The option to get the drugs at home had the highest acceptance of all. This option is attractive for half of the patients. This option has also good acceptance in patients living closer to the treatment place (less than 30 minutes). Patients living further away than 30 minutes are clearly favourable to this option with 4times more positive votes than negative votes. On the contrary of the option with the family doctor, a majority of patients living more than an hour away are also favourable to this option.

The score is not influenced by gender or age, even if elderly tend more for the option to get drugs at home. The difference is nevertheless not statistically significant.

French speaking and German speaking patients differ in acceptance of being treated by a non-specialized physician: if none of the German speaking patients was favourable to this option, 15 of the 96 French speaking patients (16\%) were favourable to it.

Distance influences the score. Patients living more than half an hour from the treatment place are more favourable to get the drugs in their family doctor's practice (OR 5.4; 95\% CI $1.9-15.6$ ) and at home (OR 5.0; 95\% CI $1.4-18.3$ ) than patients living closer (14 respectively 16 of 29 patients versus 26 respectively 46 patients of 101 patients). Patients living more than an hour from the treatment place (distance group 4) are favourable to a therapy with more side effects (score +0.3 ) which is statistically different from patients living closer (OR 24.9; 95\% CI 3.9-160.3), despite the small number of patients in distance group 4 (7 patients).

Patients living alone are more favourable to get a more expensive therapy and pay partially for the costs (OR 2.9; $95 \%$ CI $1.0-8.3)$. The difference is tightly statistically significant and the score remains negative $(-0.1)$.

\section{DISCUSSION}

We investigated whether patients who were under chemotherapy and therefore overcame a potential access barrier could imagine choosing an alternative to the actual treatment to reduce the burden of travel. Eight different options were proposed to these patients. The range of acceptability goes from "not acceptable at all" to "attractive for some patient groups". 
To renounce to the treatment is not an option for these patients. Only one patient answered "rather yes". To renounce to efficacy isn't acceptable as well in a similar extent. These patients chose to undergo a therapy and the clear answer suggests that the burden of travel is not an acceptable reason to renounce to the therapy or to renounce to efficacy.

Being treated by a non-specialized physician isn't an option for a vast majority. 15 patients were open to this option (12\%). All 15 patients were French speaking whilst none of the German speaking was favourable to this option. Further research would be necessary to understand whether this difference is due to cultural or other factors.

The idea to accept more side effects to reduce the number of journeys leads to more differentiated answers. Negative answers are a clear majority, even if the cautious "rather no" is slightly more numerous than the clear "no". Patients living more than an hour from the treatment place are favourable to this option. For this very small group in our population ( 7 patients) more side-effects seem to be an interesting option to reduce the number of journeys. An hour of travel for one way seems to be burdensome enough to make some additional side effects acceptable.

To be hospitalized is an interesting option for $15 \%$ of the patients. Acceptance tend to be higher for patients living alone $(24 \%)$ as for patients living in a multi-person household (12\%), without being statistically significantly different. Our data do not allow to identify reasons for this difference. Whether this trend is linked to a lack of social support should be investigated.

Patients living alone have also a higher acceptance of paying partially for a more expensive therapy to reduce the number of journeys. Positive and negative votes are almost balanced in this patient group, whilst negative votes are three times more frequent in the other patient group. Whether differences in income could have had an impact cannot be answered as the questionnaire didn't ask for income.

Collaboration of medical oncologists and general practitioners offers an option which is interesting for some patients: getting the drugs, which must be prescribed by the medical oncologist, in the practice of the family doctor. If a tiny majority of 66 patients is unfavourable to it, the unfavourable patients are for the majority living rather close to the treatment place (less than 30 minutes), whilst patients leaving further away are slightly more favourable to it (14 positive votes vs. 11 negative ones). Action plans to reduce burden of travel should focus on this patient group. All patients living more than 60 minutes of the treatment place are not in favour of this option. Analysis of single patient data showed that some [4] live in places without a general practitioner in the same village. This would lead anyway to a journey with potentially the need of social support and therefore to a reduction of travel time but not of the number of journeys and hence to reduced attractiveness of the option. As patients living in villages with a general practitioner [3] also refused this option other reasons for this refusal must exist.

The option to get the drugs at home had the highest acceptance of all. Nevertheless to transfer the intake just for the sake of reducing the number of journeys makes the option attractive only for half of the patients. On the contrary of the option to get the drug in the practice of the family doctor, this option has also good acceptance in patients living closer to the treatment place (less than 30 minutes) with both groups of favourable and unfavourable patients being well balanced as well in distance group 1 (less than 15 minutes) as in distance group 2 (between 15 and 30 minutes). Patients living further away than 30 minutes are clearly favourable to this option with 4times more positive votes than negative votes. On the contrary of the option with the family doctor, a majority of patients living more than an hour away are also favourable to this option. Analysis of single patient data showed that 3 of the 4 patients living in a village without a general practitioner are in favour of this option. This fits with the assumption that to reduce the travel time without reducing the number of journeys is of limited interest.

The study methodology has several limitations, particularly the voluntariness to participate to the survey and to answer to the specific questions of interest for this investigation. Socioeconomic factors as education level, income class, immigration background or size of the household were not collected, they could be essential to explain some results as $e . g$. the better acceptability to paying partially for a more expensive therapy seen in patients living alone. Ability to imagine the transfer of the drug intake to the family doctor's practice or at home is influenced by the application form. For example, an oral intake is easy to imagine for a patient who already gets an oral drug, whilst a patient who gets a longer intravenous application won't automatically think about more practical application forms as oral or subcutaneous. The answers are probably influenced by further factors which were not included in the questionnaire. as e.g. the performance status or the advancement of the disease. The questionnaire focused on the burden of travel. Whether other reasons could influence the choice of the patients cannot be answered. 


\section{CONCLUSION}

If travel to cancer treatment may be perceived or experienced as a barrier to treatment one can expect that patients sometimes would accept compromises or alternative solutions to overcome this barrier. Patients may for example accept alternative treatment modalities reducing the number of journeys. We investigated whether patients who were under chemotherapy and therefore overcame this potential access barrier could imagine choosing for this purpose an alternative to the actual treatment. Eight different options with a scale of five possible answers were proposed to these patients. The offered options didn't find important favourable resonance. Particularly to renounce to therapy or efficacy are refused by almost all patients. The transfer of the drug intake to the practice of the family doctor or preferably at home of the patient faced some acceptance. Reducing the number of journeys seems to be attractive for defined patient groups as patients with a long travel time and elderly patients. Options should be investigated in further studies dedicated to these patient groups.

These results are limited to patients under therapy and don't allow statements about other patients, e.g. patients who haven't yet made their therapy choice.

\section{DISCLOSURE}

Part of this article has been previously published in Cancer and Clinical Oncology ISSN 1927-4858(Print) ISSN 1927-4866. DOI: http://dx.doi.org/10.5539/cco.v3n2p27

\section{CONFLICT OF INTEREST}

The authors confirm that this article content has no conflict of interest.

\section{ACKNOWLEDGEMENTS}

The authors would like to gratefully acknowledge the staff of the five involved centres for their active role by encouraging patients to fill out the questionnaire. This study has been supported by an unrestricted grant from Pierre Fabre Oncology Switzerland.

\section{REFERENCES}

[1] Payne S, Jarrett N, Jeffs D. The impact of travel on cancer patients' experiences of treatment: a literature review. Eur J Cancer Care (Engl) 2000; 9(4): 197-203. [http://dx.doi.org/10.1046/j.1365-2354.2000.00225.x] [PMID: 11829366]

[2] Butow PN, Phillips F, Schweder J, White K, Underhill C, Goldstein D. Psychosocial well-being and supportive care needs of cancer patients living in urban and rural/regional areas: a systematic review. Support Care Cancer 2012; 20(1): 1-22. [http://dx.doi.org/10.1007/s00520-011-1270-1] [PMID: 21956760]

[3] Zucca A, Boyes A, Newling G, Hall A, Girgis A. Travelling all over the countryside: travel-related burden and financial difficulties reported by cancer patients in New South Wales and Victoria. Aust J Rural Health 2011; 19(6): 298-305. [http://dx.doi.org/10.1111/j.1440-1584.2011.01232.x] [PMID: 22098213]

[4] Carey M, Paul C, Cameron E, Lynagh M, Hall A, Tzelepis F. Financial and social impact of supporting a haematological cancer survivor. Eur J Cancer Care (Engl) 2012; 21(2): 169-76. [http://dx.doi.org/10.1111/j.1365-2354.2011.01302.x] [PMID: 22070745]

[5] Groux P, Anchisi S, Szucs T. Are cancer patients willing to travel more or further away for a slightly more efficient therapy? Cancer Clin Oncol 2014; 3(1): 36-42. [http://dx.doi.org/10.5539/cco.v3n1p36]

[6] Paul CL, Hall AE, Carey ML, Cameron EC, Clinton-McHarg T. Access to care and impacts of cancer on daily life: do they differ for metropolitan versus regional hematological cancer survivors? J Rural Health 2013; 29(Suppl. 1): s43-50. [http://dx.doi.org/10.1111/jrh.12020] [PMID: 23944279]

[7] Groux P, Szucs T. Geographic disparities in access to cancer care: do patients in outlying areas talk about their access problems to their general practitioners and medical oncologists and how does that impact on the choice of chemotherapy? Eur J Cancer Care (Engl) 2013; 22(6): 746-53.

[http://dx.doi.org/10.1111/ecc.12096] [PMID: 23869815]

[8] Page BR, Belnap T, Bowen RC, Gaffney DK, Sause WT. Utilization of hypofractionated breast radiotherapy and conventional breast radiotherapy in the State of Utah. Cancer Clin Oncol 2013; 2(1): 34-41.

[9] Chuba PJ, Simon MS. Trends in primary surgical and radiation therapy for localized breast cancer in the Detroit Metropolitan area $1973-1992$. Int J Radiat Oncol Biol Phys 1997; 38(1): 103-7.

[http://dx.doi.org/10.1016/S0360-3016(96)00615-3] [PMID: 9212010] 
[10] Malin JL, Schuster MA, Kahn KA, Brook RH. Quality of breast cancer care: what do we know? J Clin Oncol 2002; 20(21): 4381-93. [http://dx.doi.org/10.1200/JCO.2002.04.020] [PMID: 12409338]

[11] Tuttle TM, Habermann EB, Grund EH, Morris TJ, Virnig BA. Increasing use of contralateral prophylactic mastectomy for breast cancer patients: a trend toward more aggressive surgical treatment. J Clin Oncol 2007; 25(33): 5203-9. [http://dx.doi.org/10.1200/JCO.2007.12.3141] [PMID: 17954711]

[12] Dwyer P, Hickey B, Burmeister E, Burmeister B. Hypofractionated whole-breast radiotherapy: impact on departmental waiting times and cost. J Med Imaging Radiat Oncol 2010; 54(3): 229-34. [http://dx.doi.org/10.1111/j.1754-9485.2010.02163.x] [PMID: 20598011]

[13] Busato A, Künzi B. Primary care physician supply and other key determinants of health care utilisation: the case of Switzerland. BMC Health Serv Res 2008; 8: 8 . [http://dx.doi.org/10.1186/1472-6963-8-8] [PMID: 18190705]

[14] Anchisi S, Anchisi A. Vivre la chimiothérapie au quotidien: un processus qui révèle l'âge. Bull Cancer 2008; 95(suppl. FMC): F44-50.

[15] Groux P, Anchisi S, Szucs T. How do gender, age and travel time impact on the need for social support of patients to have access to cancer treatment? Cancer Clin Oncol 2014; 3(2): 27-35. [http://dx.doi.org/10.5539/cco.v3n2p27]

[16] Kirkwood BR and Sterne J. Medical Statistics. $2^{\text {nd }}$ ed. Malden, USA: Blackwell Science Publishing 2003.

(C) Groux et al.; Licensee Bentham Open

This is an open access article licensed under the terms of the Creative Commons Attribution-Non-Commercial 4.0 International Public License (CC BY-NC 4.0) (https://creativecommons.org/licenses/by-nc/4.0/legalcode), which permits unrestricted, non-commercial use, distribution and reproduction in any medium, provided the work is properly cited. 